reducing metabolic rate and of breathing oxygen at low partial pressures to save weight in food and oxygen. Dr. Pugh also made the important point that while lack of preparation had been the undoing of many previous explorations, the ultimate test of performance is in the real situation.

Flt. Lt. J. Billingham, of the R.A.F. Institute of Aviation Medicine, examined the problems of heat exchange between man and the sealed cabin, and proposed a specification for environmental conditions during interplanetary flight. $\mathrm{He}$ also presented a paper on heat exchange between man, his pressure suit and the environment on the surface of the Moon.

Dr. K. F. Jackson, of the R.A.F. Institute of Aviation Medicine, read a paper on the impairment of human performance in control. He presented the results of an investigation into the factors affecting performance of the crews of long-range reconnaissance aircraft, with particular reference to fatigue. $\mathrm{H}_{\Theta}$ also demonstrated a portable version of his multiple tracking test apparatus, which provides measurements of about ten different aspects of performance.

Mr. C. Cunningham, from the Air Ministry, described the effects of sensory impoverishment, confinement and deprivation of sleep. If these are allowed to continue unchecked for a number of days, the result is changes in the personality and the intellect, often to a degree where logical thought and action become impossible. His evidence was obtained from experimental work, particularly that of Hebb, and from the experiences of former prisoners. There is no doubt that these factors will be of paramount importance in space travel, especially in the case of journeys lasting for years.

Dr. A. S. Parkes and Dr. Audrey V. Smith, of the National Institute for Medical Research, directed attention in their paper on the transport in space of life in the dried or frozen state to the considerable economy of carrying some of the crew of a space vehicle in a state of suspended animation. They considered, however, that the possibility of freezing man was remote. On the other hand, there should be less difficulty in landing spores and seeds on another planet.

Mr. S. W. F. Hanson, of the Ministry of Agriculture, discussed the very practical problems of feeding during travel in space, and the difficulties in the maintenance of a biological cycle, including plants, for journeys of long duration.

The final speaker was Dr. A. E. Slater, of the British Interplanetary Society, who must take credit for the organization of the symposium. He discussed the hazards to man of the radiation belt revealed by the Explorer satellites. A region of intense radiation exists between latitudes $30^{\circ} \mathrm{N}$. and $30^{\circ} \mathrm{S}$. of the magnetic equator. Singer attributed this belt to protons captured in the Earth's magnetic field, and his theory has received considerable support from the information received from the American rocket Pioneer, which showed the radiation to be maximal at an altitude of 5,70 miles. Dr. Slater concluded on an optimistic note, describing a suggestion by Singer that the radiation belt could be mopped up in one year by a satellite some ten metres in diameter travelling in an appropriate orbit. J. BILLINGHAM

\title{
CHEMICAL PATHOLOGY OF THE NERVOUS SYSTEM
}

$\mathrm{T}$ HE subject of the third International Neurochemical Symposium, which was held in the University of Strasbourg during August 25-29, was "The Chemical Pathology of the Nervous System". Several facets of this ramifying topic were discussed by experts from a number of countries, and as those attending the Symposium were restricted to a comparatively small number (130) there were often vigorous and satisfying discussions. As in previous similar symposia, the main subjects were subdivided so that there could be reviews followed by short individual papers on related topics.

A whole day was devoted to metabolic disorders, and the inborn errors of metabolism received detailed attention from Dr. G. A. Rose (London) and Dr. G. A. Jervis (New York). Dr. Rose described a new form of mental defect characterized by the excretion of arginosuccinic acid, and suggested that mental defect may, in fact, include a large group of metabolic diseases of which 'arginosuccinuria' is one, the biochemical lesion in this condition being the inability to split arginosuccinic acid into arginine and fumaric acid.

In this section, too, there were interesting papers on phenylketonuria and Hartnup's disease (Dr: R. Rodnight, London), and the subject of the cerebral lipidoses was also discussed. In connexion with cerebral lipidoses, Dr. M. Lees (Boston) pointed out that analytical methods suitable for normal brain tissue may not necessarily be applicable to pathological material. It was obvious, too, that much more precise information on the chemical nature of brain gangliosides and sulphatides is desirable if rapid progress is to be made in this field. Dr. H. M. Sinclair (Oxford), reviewing the subject of metabolic disorders of nutritional origin, emphasized the wide variety of dietary substances necessary for the adequate maintenance of a 'normal' nervous system.

Prof. J. M. Cumings (London), in a comprehensive review of the chemical pathology of copper, paid particular attention to the copper protein present in brain tissue and its possible significance. The chemical nature of cerebrocuprein in normal brain and that obtained from the brain of individuals suffering from Wilson's disease (hepatolenticular degeneration) was then discussed by Dr. H. Porter (Boston), who has found a significant difference in the chemical properties and electrophoretic mobilities of the two proteins. Members of the Symposium found this an exciting new observation.

The fact that a considerable number of biochemical investigations have been carried out on demyelination processes was reflected in a number of interesting papers on this topic. A review of demyelination in general was given by Dr. R. D. Adams (Boston), and a masterly and concise account of Wallerian degeneration by Prof. R. Rossiter (London, Canada) vividly demonstrated to the audience how precise chemical studies can be used to map a pathological process. Dr. E. Robins's (St. Louis) studies on the biochemistry of chromatolysis in individual anterior horn cells after axonal section illustrated the signifi- 
cance of analysis of individual cells in a heterogeneous system. The importance of developing new techniques in investigations of this kind cannot be overemphasized. Dr. A. Lajtha (Now York) presented isotopic evidence suggesting that protein synthesis occurs continuously in the nerve cell body and that there is a flow of protein down the axon. Nissl granules, which are apparently essential for protein synthesis; are absent from the axon.

In a survey based largely on his own experimental observations, Dr. K. A. C. Elliot (Montreal) discussed the problem of swelling and shrinkage in nervous tissue. This was supplemented by Prof. E. W. Dempsey's (St. Louis) account of electron microscopic studies on nervous tissue. He informed the audience that there is an interstitial space in brain tissue which is not negligible. The uptake of fluid into oligodendroglial cells is one way in which swelling can take place.

Under the broad heading of "The Chemistry of Convulsive States and Allied Disorders" there were a number of reports on the significance of $\gamma$-aminobutyric acid, glutamic acid and glutamine in brain tissue. For some years the relatively high concentration of these three substances has aroused interest, and further investigations have now been stimulated by the finding that 'Factor I' activity is intrinsically associated with $\gamma$-aminobutyric acid. Glutamic acid and $\gamma$-aminobutyric acid appear to have opposite effects in brain tissue, and Dr. E. Roberts (Duarte) remarked that the relative levels of glutamic acid and $\gamma$-aminobutyric acid may be determined by the intracellular $p \mathrm{H}$.

Prof. H. McIlwain (London) gave an interesting discourse on some of his more recent studies on the electrical stimulation of isolated brain tissue. $\mathrm{He}$ has found that the subcortical white matter gives a much better response to localized stimulation on the surface than does grey matter, suggesting that the response is transmitted through the white matter. In further experiments Prof. McIlwain has also succeeded, for the first time, in obtaining resting potentials from isolated white matter.

The last two days of the meeting were devoted to the biochemistry of mental disease, in which a considerable amount of research is now being carried out. Dr. A. Pope (Waverley) impressed everyone with his account of the distribution of certain enzymes in various cellular layers of the isocortex of normal and psychotic subjects. Biopsy material from leucotomy operations was used, and the studies may well be unique in that, with the increasing use of tranquillizing drugs, the number of leucotomy operations is being rapidly reduced, cutting off the source of material. In the event, there did not appear to be any specific difference between the enzyme distribution in normal and psychotic individuals so far as the isocortex is concerned.

Dr. M. Reiss (New York) reviewed the importance of hormone studies in mental disease and the value of considering the human organism as a whole. Carbohydrate metabolism in mental disease was reviewed by Dr. H. E. Himwich (Galesburg) with special reference to blood-sugar tolerance curves. Dr. Himwich also discussed whether or not the psychotic individual responds to biochemical stress in the same way that the normal does. The problem of glucose utilization by schizophrenics was discussed by Dr. M. D. Altschule (Waverley), who suggested a direct relationship between the mental state of the individual and the capacity to metabolize carbohydrate. Several members of the audience disagreed with this observation.

In a survey of the relationship between protein metabolism and mental disease, Dr. D. Richter (Cardiff) emphasized the great lack of basic knowledge on the nature of the proteins of the central nervous system. No protein had been well characterized to date, and until this was done progress would be slow, although some advances had been made by electrophoretic methods. It was obvious that the infinite possible variations in the structure of proteins could well be of significance in the nervous system, and different proteins appeared to exist in different parts of the brain. Dr. Richter also pointed out that in many mental disorders there was evidence of developmental failure which might be related to deficiencies in protein metabolism. For example, the mongol brain had an 'unfinished' appearance. while epileptic seizures might be considered to represent a persistence of embryonic convulsions. Furthermore, the fact that twenty-five per cent of all schizophrenic symptoms commenced in the period from 15 to 25 years of age, suggests a relationship between the disease and maturation changes.

If knowledge on brain protein metabolism is scanty, the same cannot be said for the metabolism of amines. A vast amount of research is now under way on the metabolism of amines and their pharmacological effects. Thus it is becoming hard to keep abreast of the large number of published studies on 5-hydroxytryptamine. In his review on the metabolism of amines in mental disease, Dr. E. A. Zeller (Chicago) stated that chromatograms of the amines present in the urines of normal subjects showed that more than thirty different amines could be detected. The urines of schizophrenics gave a different pattern: but very few of the amines had been identified. Prof. H. Waelsch (New York) gave an account of some new results from his laboratory which showed that in vitro certain liver protein fractions can take up amines labelled with carbon-14 in covalent linkage. the amine displacing ammonia, probably from the $\varepsilon$-amino group of lysine. The possibility that amines might form modified proteins in this way provoked a long discussion. Some fresh experiments on epinephrine metabolism were then presented by $\mathrm{Dr}$. J. Axelrod (Bethesda), who stated that the formation of adrenochrome is a most unlikely step in epinephrine catabolism. In support of this he has now shown that the major metabolite of epinephrine labelled with tritium is a methylated compound (metanephrine). An enzyme capable of methylating epinephrine is apparently widely distributed. Interesting paper's by Dr. T. L. Sourkes (Montreal) and Dr. H. WeilMalherbe (Washington), on the urinary excretion of catecholamines by psychotic individuals, underlinerl the current interest in aborrations of amine meta. bolism.

In a closing speech Dr. S. S. Kety (Bethesda) analysed theories of the biochemical etiology of mental disease. In a satisfying and illuminating way he reviewed the work of those investigators who hav concluded that this or that toxic substance, or group of substances, is characteristic of mental disorder, and his conclusion was that no one has convincingly demonstrated a biochemical lesion characteristic of the psychoses. The recent studies on ceruloplasmin, thought to be present in increased amounts in schizophrenic plasma, have proved to be incorrect, while the reports on taraxein, a toxic factor from 
schizophrenic blood, have proved equivocal. Dr. Kety affirmed that it was most difficult to plan experiments to compare psychotics with normal controls. To obtain proper controls was a considerable feat in itself, and most research had been carried out on patients in institutions who had, among other things, been on an unusual diet. This latter consideration often accounted for reports of the atypical urinary constituents of mental patients. The subconscious desire on the part of the investigator to eliminate conflicting data had also to be overcome. There was considerable discussion after Dr. Kety's paper on the problems inherent in undertaking bio- chemical studies in mental disease, and one or two speakers put in a plea for investigators to publish negative findings, if only to eliminate duplication of effort.

Altogether the Strasbourg conference was a stimulating experience and thanks are due to the organizing committee for the first-class presentation. All members of the Symposium are indebted also to Prof. Mandel and the Comite de Patronage for the hospitality shown in Strasbourg, and no one will easily forget the many social events organized for the delight of members, especislly the outing to Obernai.
G. B. ANSELI

\section{HUMAN AND ANIMAL MYCOLOGY}

$\mathrm{T}$ HE International Society for Human and Animal Mycology met in Lisbon during September 5-10. The meeting, the first since the Society was founded in Paris in 1954, was held by permission of the President and General Secretary of the Sixth International Congresses on Tropical Medicine and Malaria. It was attended by more than sixty members of the Society, and twenty-one countries, including the U.S.S.R., Japan, the United States, Brazil, South Africa and Australia, were represented.

Three of the sessions on tropical medicine were devoted to mycotic infections, and these covered the clinical and epidemiological aspects of mycoses, the ecology and saprophytic occurrence of pathogenic fungi and the biochemistry and physiology of pathogenic fungi. In addition, the Society held two business meetings and three paper-reading sessions. Altogether there were more than forty communications, and ample time was allowed for discussion.

In a brief report of the proceedings it is difficult to select, from the many papers presented, those most worthy of note. However, no account would be complete without reference to the contributions on the ecology of pathogenic fungi. Dr. C. W. Emmons (United States) pointed out that, for many of the mycoses, we know that saprophytic growths provide the inocula from which man and animals are infected, and that all epidemiological evidence suggests the probability of saprophytic sources of inocula for a number of other mycoses. He suggested that attempts to isolate the fungi from soil of areas where the specific mycoses are endemic, and a more careful comparison of certain rare pathogens with fungi already described in the literature of general mycology may well increase or complete the list of pathogens with known saprophytic sources. Dr. Emmons said that most of the pathogens of man have a wide geographical distribution and their local distribution is dependent upon ecological factors only partially recognized.

The results of a four-year study of Coccidioides immitis in the soil of the South-West Joaquin Valley of California were given by Dr. Egeberg (United States). He discussed the ecological and epidemiological significance of the recovery-rate of the fungus being highest in surface soil three to four weeks after the end of the rainy season, most consistent from the walls of animal burrows, and lowest from the surface towards the end of the dry season when the incidence of the disease is at its highest.

Dr. P. Abbot (Britain), in his consideration of mycetoma, noted that for this disease the incidence is apparently correlated with climatic conditions rather than with specific soil types or other factors. The recovery of the dermatophytes Microsporum canis, $M$. gypseum and the non-pathogenic keratinophilic fungi Trichophyton terrestre, which is a new species, and Keratinomyces ajelloi from the soil of Australia and New Guinea was discussed by Dr. E. B. Durie (Australia), who also reviewed previous work on the ecology of dermatophytes. In his consideration of the mouth as a reservoir of pathogenic fungi, Dr. G. C. Ainsworth (Britain) pointed out that of the many and diverse fungi recorded from the mouth, most are 'contaminants' and only a small number may be considered as 'inhabitants'. Some of the 'inhabitants' appear to provide a reservoir of infection for such endogenous diseases as candidiasis and actinomycosis. A single isolation of Cryptococcus neoformans from a healthy horse, during his investigations into the intestinal yeast flora of man and domestic animals, was reported by Dr. N. Van Uden (Portugal). This pathogenic yeast has been shown in the United States to be frequently associated with pigeon droppings, and Dr. K. Ishida (Japan) reported similar findings in Tokyo.

Histoplasmosis was the subject of a number of contributions. The first occurrence of this disease in Japan was reported by Dr. H. Yamato, and a paper on the distribution of histoplasmosis in South Africa was given by Dr. H. I. Lurie. Dr. E. Drouhet (France) and Dr. J. Schwarz (United States) both reported that in culture there is no apparent difference between Histoplasma duboisii, first described by Vanbreuseghem in 1952, and $H$. capsulatum. However, the geographical distribution and the clinical and pathological aspects of African histoplasmosis caused by $H$. duboisii differ considerably from the classic form of the disease caused by $\boldsymbol{H}$. capsulatum, and it was generally agreed that for the present it is useful to consider them separately.

In an interesting communication Dr. A. C. Batista (Brazil) stated that from the results of investigations carried out in Brazil it is clear that fungi such as Candida and Torulopsis may be a primary cause of cholecystitis. Dr. C. S. da Silva Lacaz (Brazil) gave an excellent account of the clinical and epidemiological 